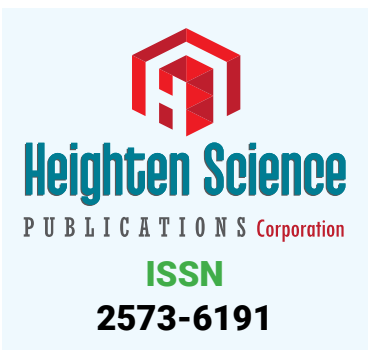

*Address for Correspondence: Alberto J Kalach Mussali, Avenida Baja Velocidad Speed 284, Colonia San Jerónimo Chicahualco, Metepec, State of Mexico, Mexico, C.P. 52170, Tel: +52722-275-6300; Email: albertokalach@gmail.com

Submitted: 05 December 2018

Approved: 03 June 2019

Published: 04 June 2019

Copyright: @ 2019 Kalach Mussali AJ, et al. This is an open access article distributed under the Creative Commons Attribution License, which permits unrestricted use, distribution, and reproduction in any medium, provided the original work is properly cited

Keywords: Bilateral sagittal split osteotomy; Mandibular condyle position; Temporomandibular joint; Clinical dysfunction index; Orthognathic surgery

A) Check for updates
Research Article

\section{Correlation between mandibular condylar position and clinical dysfunction index after bilateral sagittal split osteotomies}

\author{
Kalach Mussali Alberto $\mathrm{J}^{1 *}$ Gonzalez-Magana Fernando ${ }^{2}$ and \\ Malagon Hidalgo Hector $\mathrm{O}^{3}$ \\ ${ }^{1}$ Resident, Plastic \& Reconstructive Surgery, ISSEMyM Medical Center, Toluca, State of Mexico, \\ Mexico \\ ${ }^{2}$ Clinical Assistant Professor, Maxillofacial Surgery, ISSEMyM Medical Center, Toluca, State of \\ Mexico, Mexico \\ ${ }^{3}$ Program Director, Plastic \& Reconstructive Surgery, ISSEMyM Medical Center, Toluca, State of \\ Mexico, Mexico
}

\section{Summary}

Several articles have discussed mandibular condyle position after bilateral sagittal split osteotomies (BSSO). However, previous studies have sought to establish a relationship between orthognathic surgery and the improvement of temporomandibular joint (TMJ) signs and symptoms. Also, they have been limited to two-dimensional evaluation of condylar position considering only the condylar "sag" or improper inferior seating of the condyle. The purpose of this study was to investigate a relationship between changes in condylar position using three-dimensional computed tomography and the negative clinical impact of BSSO on the temporomandibular joint.

\section{Introduction}

Dentofacial deformities can be defined as significant deviations from normal proportions of the maxillo-mandibular complex that also negatively affect the relationship of the teeth within each arch and the relationship of the arches with one another (occlusion). These deformities may be minimal, such as a slight projection of the chin, or extreme, such as a severe vertical maxillary excess or hemifacial microsomia [1]. This condition may be evident at birth or appear during growth and development, creating functional, degenerative, aesthetic and psychosocial problems [2]. Serious problems of dental and skeletal malocclusion require combined treatment with orthodontics and orthognathic surgery, intending to achieve facial, dental and functional harmony [3].

Surgery to reposition the jaws (i.e., an orthognathic procedure) as part of an interdisciplinary approach is often recommended to manage the related skeletal, dental, and soft-tissue dysfunctions and concerns [4]. Orthognathic surgery is a treatment option that provides stability, function and aesthetics [5].

The most common orthognathic procedure is a bilateral sagittal split osteotomy to advance the mandible in cases of mandibular deficiency [6]. Mandibular advancement, setback and rotation have an effect and change in mandibular topography and its relationships [5]. Some patients with preoperative symptoms have an improvement after surgical correction, but for some patients the symptoms may change for the worse $[7,8]$. mandibular condylar position and clinical dysfunction index after bilateral sagittal split osteotomies. $J$ Oral Health Craniofac Sci. 2019; 4: 001-007. https://doi.org/10.29328/journal.johcs.1001026 
Mandibular topographic changes have a displacement of the mandibular condyle within the temporomandibular joint, leading to temporomandibular disorders [9]. The potential effects of BSSO on signs and symptoms of temporomandibular joint disorder are still controversial. The surgeon must be aware of the potential implication of BSSO advancement on the onset and progression of temporomandibular disorders in patients with Class II malocclusion. Interestingly, counterclockwise rotation of the mandible appears to be associated with more muscle tenderness, especially in patients undergoing greater BSSO advancements [10]. Mandibular condyle displacements after BSSO may cause temporomandibular joint dysfunction; the aim of this study is to investigate the relationship between the clinical dysfunction index and the mandibular condyle position after BSSO [10].

\section{Material and Methods}

A population of 47 patients who underwent BSSO in the Maxillofacial / Plastic \& Reconstructive Surgery Department in ISSEMyM Medical Center were studied retrospectively. All of the patients had preoperative orthodontics and they were operated between December 2012 and January 2016. During preoperative and postoperative examination, Helkimo's Anamnestic and Dysfunction Index (HADI) [11], were determined. Three-dimensional computed tomography were acquired with $1.0 \mathrm{~mm}$-thick slices using a Siemens SOMATOM Emotion scanner, data acquisition occurred in the preoperative surgical planning and $>6$ months postoperatively for both the Helkimo's Anamnestic and Dysfunction Index and tomographic measurements using Pullinger \& Hollender modified by Pereira method (P\&HmP) [12]. (to determine antero-posterior condylar displacement) and determination of condylar rotation as seen in figure 1 (ConRot) (determined in the axial plane parallel to Frankfort's plane, tracing a line between the anterior and posterior nasal spine determining the midsagittal plane; and a line on the mayor condylar axis, resulting in an angle) $[13,14]$.

Each examination included a written anamnestic questionnaire and both a clinical and radiological examination. In the questionnaire the patient answered yes or no to questions concerning joint noises, locking, joint pain, pain in the facial musculature, stiffness/difficulties in mouth opening, clenching of the teeth and ear pain. The basic data from the questionnaire and clinical examination were calculated and classified according to Helkimo's Anamnestic Index and clinical Dysfunction Index.

Statistical analysis was performed using SPSS 24.0 software measuring Pearson's correlation coefficient to establish a relationship between tomographic measurements and Helkimo's Anamnestic and Dysfunction Indexin the preoperative and postoperative setting.

This study received approval from the institutional review of boards and ethics committee approval.

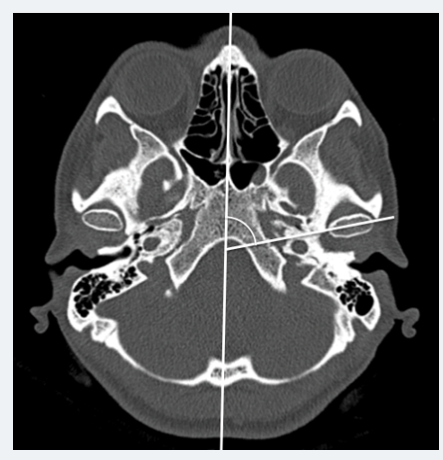

Figure 1: Anamnestic and Dysfunction Index and tomographic measurements using Pullinger \& Hollender modified by Pereira method (P\&HmP) (to determine antero-posterior condylar displacement) and determination of condylar rotation. 


\section{Results}

Data was gathered from 47 patients for statistical analysis shown in table 1 . There were no significant differences between the Helkimo's Anamnestic and Dysfunction Index and the tomographic measurements in the preoperative setting. A weak correlation was found between condylar displacement (P\&HmP) and HADI with a Pearson's correlation coefficient of $0.175(\mathrm{p}=0.091)$ as seen in figure 2; nor condylar rotation and HADI with a Pearson's correlation coefficient of $0.158(\mathrm{p}=0.129)$ as seen in figure 3.

During the postoperative period, patients with a posterior mandibular condyle displacement in the temporomandibular joint showed a higher HADI score, proving

Table 1: Data was gathered from 47 patients for statistical analysis.

\begin{tabular}{|c|c|c|c|c|c|c|c|c|}
\hline Patient & Date of Surgery & $\begin{array}{c}\text { Time Lapse } \\
\text { between CT } \\
\text { (months) }\end{array}$ & $\begin{array}{c}\text { Preoperative } \\
\text { HADI }\end{array}$ & $\begin{array}{c}\text { Postoperative } \\
\text { HADI }\end{array}$ & Preoperative P\&HmP & Postoperative P\&HmP & $\begin{array}{c}\text { Preoperative } \\
\text { ConRot }\end{array}$ & $\begin{array}{c}\text { Postoperative } \\
\text { ConRot }\end{array}$ \\
\hline 1 & $07 / 02 / 13$ & 15 & 3 & 2 & $-9.38 / 2.33$ & $6.25 /-4.48$ & $56 / 63$ & $66 / 71$ \\
\hline 2 & $14 / 02 / 13$ & 7 & 1 & 12 & $-20.00 /-16.46$ & $-52.94 /-36.84$ & $76 / 72$ & $68 / 67$ \\
\hline 3 & $21 / 03 / 13$ & 17 & 1 & 2 & $0.00 / 3.33$ & $-6.49 / 5.08$ & $73 / 73$ & $75 / 77$ \\
\hline 4 & $28 / 03 / 13$ & 10 & 1 & 2 & $10.77 / 12.33$ & $9.33 / 0.00$ & $77 / 81$ & $74 / 84$ \\
\hline 5 & $02 / 05 / 15$ & 14 & 4 & 6 & $13.04 /-18.84$ & $8.33 / 8.57$ & $59 / 64$ & $64 / 63$ \\
\hline 6 & $09 / 05 / 13$ & 13 & 1 & 8 & $-1.30 /-12.77$ & $-25.93 /-4.76$ & $68 / 70$ & $78 / 79$ \\
\hline 7 & $29 / 05 / 13$ & 11 & 6 & 1 & $12.33 / 11.36$ & $5.13 / 11.36$ & $71 / 73$ & $78 / 78$ \\
\hline 8 & $13 / 06 / 13$ & 18 & 3 & 8 & $9.76 / 8.33$ & $11.32 / 10.64$ & $76 / 75$ & $66 / 74$ \\
\hline 9 & $27 / 06 / 13$ & 24 & 2 & 5 & $14.29 /-13.33$ & $-7.25 / 3.33$ & $66 / 71$ & $68 / 79$ \\
\hline 10 & $02 / 08 / 13$ & 23 & 3 & 0 & $-9.68 /-6.90$ & $11.11 /-9.38$ & $68 / 71$ & $76 / 74$ \\
\hline 11 & $22 / 08 / 13$ & 14 & 3 & 4 & $15.63 /-13.43$ & $-18.31 / 6.45$ & $74 / 77$ & $76 / 76$ \\
\hline 12 & 29/08/13 & 20 & 4 & 2 & $-8.33 /-9.68$ & $-14.89 /-7.41$ & $54 / 62$ & $68 / 73$ \\
\hline 13 & $12 / 09 / 13$ & 14 & 1 & 1 & $2.94 / 12.90$ & $-12.73 /-8.77$ & $88 / 62$ & $84 / 66$ \\
\hline 14 & $13 / 12 / 13$ & 19 & 4 & 1 & $-7.94 /-7.41$ & $-8.77 /-3.03$ & $65 / 76$ & $74 / 77$ \\
\hline 15 & $13 / 12 / 13$ & 9 & 1 & 1 & $2.86 /-1.20$ & $2.86 /-11.69$ & 73/78 & $71 / 74$ \\
\hline 16 & $20 / 02 / 14$ & 14 & 4 & 3 & $-2.63 /-5.08$ & $-7.04 /-7.14$ & $69 / 71$ & $73 / 75$ \\
\hline 17 & $08 / 05 / 14$ & 16 & 2 & 3 & $7.89 / 0.00$ & $7.14 /-4.92$ & $68 / 71$ & $66 / 70$ \\
\hline 18 & $22 / 05 / 14$ & 13 & 0 & 1 & $-8.77 /-2.56$ & $-5.41 / 2.94$ & $80 / 79$ & $82 / 80$ \\
\hline 19 & $29 / 05 / 14$ & 10 & 2 & 4 & $12.00 / 11.48$ & $18.31 / 18.18$ & $77 / 80$ & $82 / 78$ \\
\hline 20 & $01 / 06 / 14$ & 11 & 2 & 2 & $3.70 / 1.33$ & $4.35 / 6.49$ & $74 / 74$ & $73 / 75$ \\
\hline 21 & $04 / 06 / 14$ & 9 & 3 & 2 & $4.23 /-7.46$ & $11.83 / 1.23$ & $79 / 74$ & $74 / 75$ \\
\hline 22 & $19 / 06 / 14$ & 12 & 3 & 5 & $-10.77 / 19.44$ & $-2.94 / 1.59$ & $74 / 76$ & $77 / 73$ \\
\hline 23 & $26 / 06 / 14$ & 8 & 1 & 1 & $-3.53 / 0.00$ & $2.22 / 5.75$ & $72 / 71$ & $74 / 74$ \\
\hline 24 & $18 / 07 / 14$ & 8 & 4 & 7 & $-20.51 /-19.51$ & $8.89 / 10.59$ & $70 / 72$ & $79 / 78$ \\
\hline 25 & $18 / 09 / 14$ & 21 & 2 & 0 & $-2.63 / 7.94$ & $-15.91 / 2.50$ & 70/71 & $72 / 68$ \\
\hline 26 & $27 / 11 / 14$ & 17 & 1 & 4 & $-11.11 / 27.27$ & $-12.50 / 8.16$ & 73/70 & $83 / 76$ \\
\hline 27 & $11 / 12 / 14$ & 19 & 1 & 3 & $-14.29 /-7.69$ & $-1.33 /-1.33$ & $69 / 64$ & $73 / 59$ \\
\hline 28 & $14 / 12 / 14$ & 15 & 2 & 6 & $-7.04 / 0.00$ & $2.70 /-17.14$ & $76 / 76$ & $73 / 75$ \\
\hline 29 & $27 / 02 / 15$ & 13 & 2 & 0 & $-5.88 /-9.86$ & $-8.77 /-10.00$ & $81 / 80$ & $77 / 75$ \\
\hline 30 & $27 / 04 / 15$ & 14 & 2 & 13 & $-28.57 / 13.51$ & $-43.86 / 24.53$ & $69 / 64$ & $63 / 59$ \\
\hline 31 & $16 / 07 / 15$ & 16 & 0 & 1 & $-13.04 /-10.34$ & $-22.22 /-11.63$ & $71 / 69$ & $70 / 67$ \\
\hline 32 & $25 / 09 / 15$ & 12 & 2 & 1 & $-1.69 / 5.08$ & $1.64 /-6.06$ & $77 / 79$ & $76 / 77$ \\
\hline 33 & $27 / 09 / 15$ & 10 & 2 & 2 & $1.64 /-2.94$ & $-7.94 /-4.92$ & $81 / 83$ & $78 / 80$ \\
\hline 34 & $02 / 10 / 15$ & 9 & 6 & 4 & $14.61 / 12.00$ & $3.37 / 5.75$ & $79 / 81$ & $84 / 79$ \\
\hline 35 & $08 / 10 / 15$ & 9 & 0 & 6 & $-5.88 /-10.34$ & $12.00 /-9.38$ & $76 / 74$ & $70 / 80$ \\
\hline 36 & $23 / 10 / 15$ & 14 & 3 & 11 & $12.12 / 5.08$ & $-30.43 / 22.22$ & $64 / 72$ & $55 / 72$ \\
\hline 37 & $06 / 11 / 15$ & 11 & 1 & 1 & $2.50 /-1.27$ & $0.00 / 6.67$ & $77 / 78$ & $81 / 82$ \\
\hline 38 & 29/11/15 & 7 & 2 & 4 & $2.94 / 7.25$ & $11.43 /-11.39$ & $78 / 73$ & $74 / 79$ \\
\hline 39 & $22 / 01 / 16$ & 11 & 9 & 3 & $2.56 /-5.71$ & $0.00 /-8.33$ & $74 / 73$ & $77 / 81$ \\
\hline 40 & $23 / 02 / 16$ & 12 & 4 & 1 & $-2.86 / 7.89$ & $-11.43 /-5.26$ & $81 / 74$ & $76 / 75$ \\
\hline 41 & 08/04/16 & 11 & 2 & 0 & $-12.28 /-7.94$ & $-9.09 /-3.13$ & $84 / 79$ & $80 / 76$ \\
\hline 42 & $23 / 06 / 16$ & 7 & 1 & 3 & $6.49 /-2.86$ & $-6.49 / 1.23$ & $75 / 75$ & $71 / 77$ \\
\hline 43 & $22 / 09 / 16$ & 12 & 3 & 2 & $20.00 /-3.45$ & $-9.68 / 11.83$ & $78 / 70$ & $73 / 74$ \\
\hline 44 & $06 / 10 / 16$ & 6 & 6 & 2 & $5.13 / 16.22$ & $4.65 / 7.14$ & $69 / 79$ & $76 / 74$ \\
\hline 45 & $02 / 12 / 16$ & 8 & 3 & 1 & $5.45 /-11.43$ & $-6.25 / 3.45$ & $83 / 69$ & $74 / 77$ \\
\hline 46 & $09 / 12 / 16$ & 6 & 1 & 4 & $17.14 /-17.24$ & $-15.49 /-4.44$ & $71 / 79$ & $79 / 73$ \\
\hline
\end{tabular}




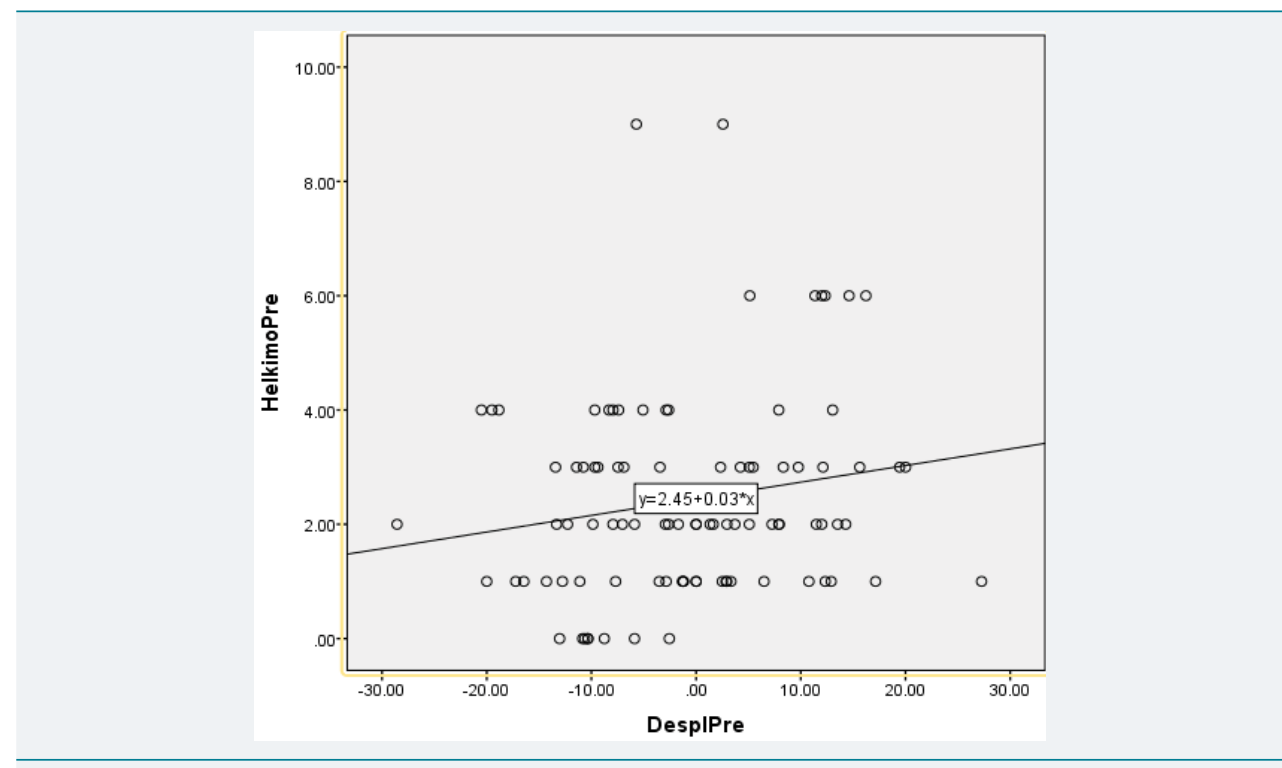

Figure 2: A weak correlation was found between condylar displacement (P\&HmP) and HADI with a Pearson's correlation coefficient of $0.175(\mathrm{p}=0.091)$.

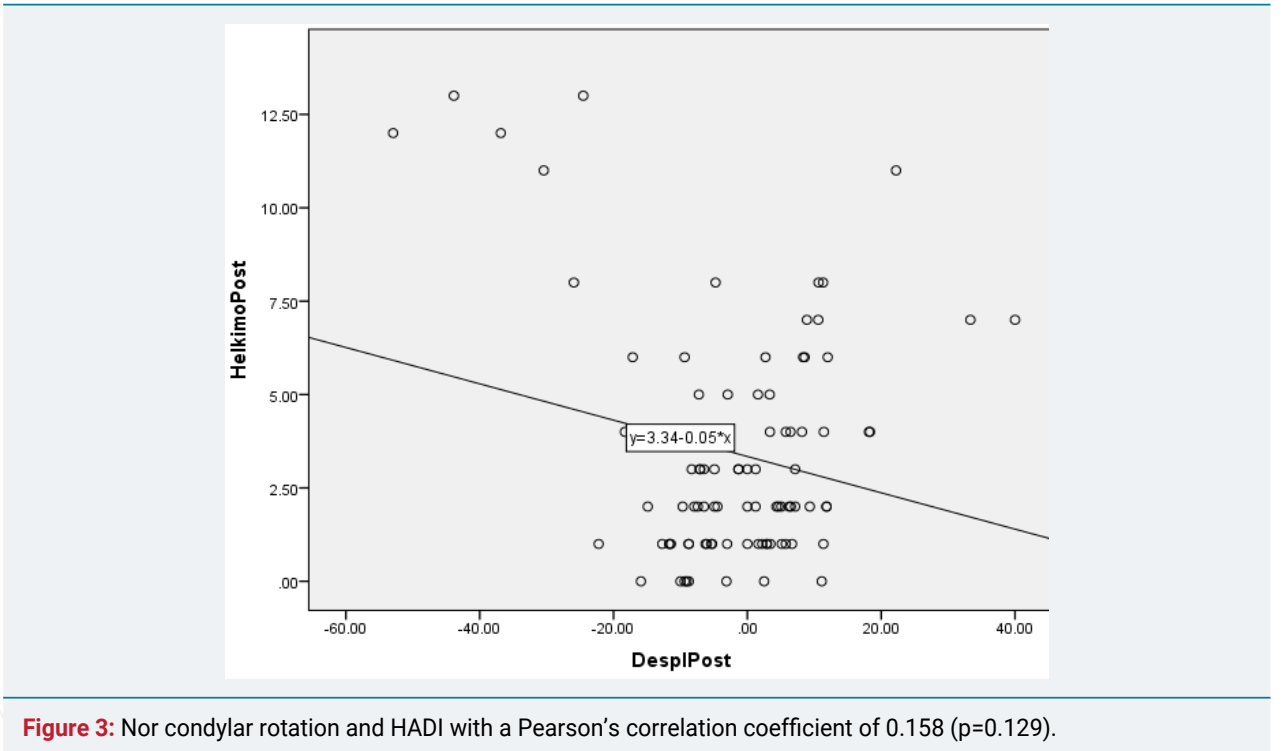

Figure 3: Nor condylar rotation and HADI with a Pearson's correlation coefficient of $0.158(p=0.129)$.

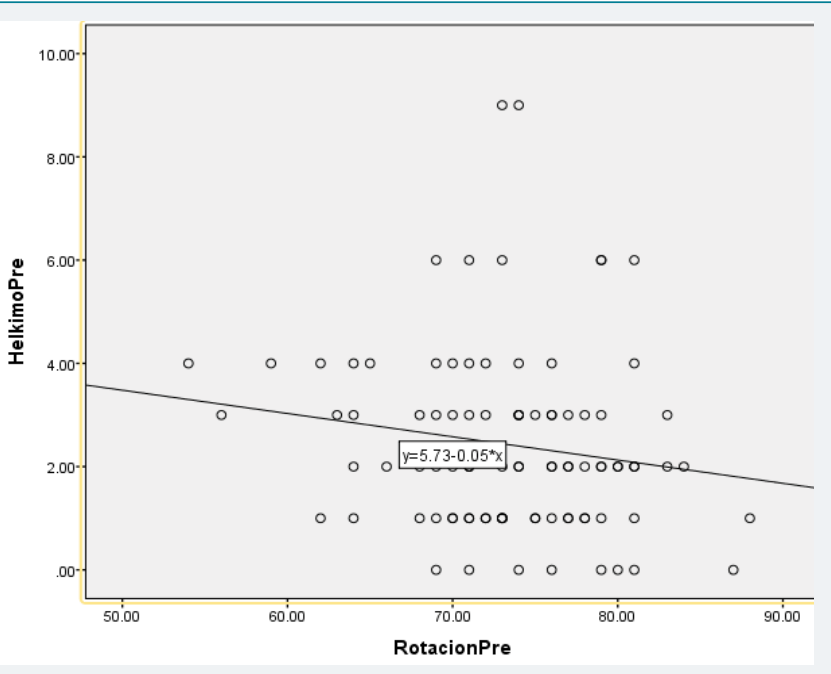

Figure 4: A posterior mandibular condyle displacement in the temporomandibular joint showed a higher HADI score, proving a strong Pearson's correlation coefficient with a score of $-0.217(p<0.036)$. 


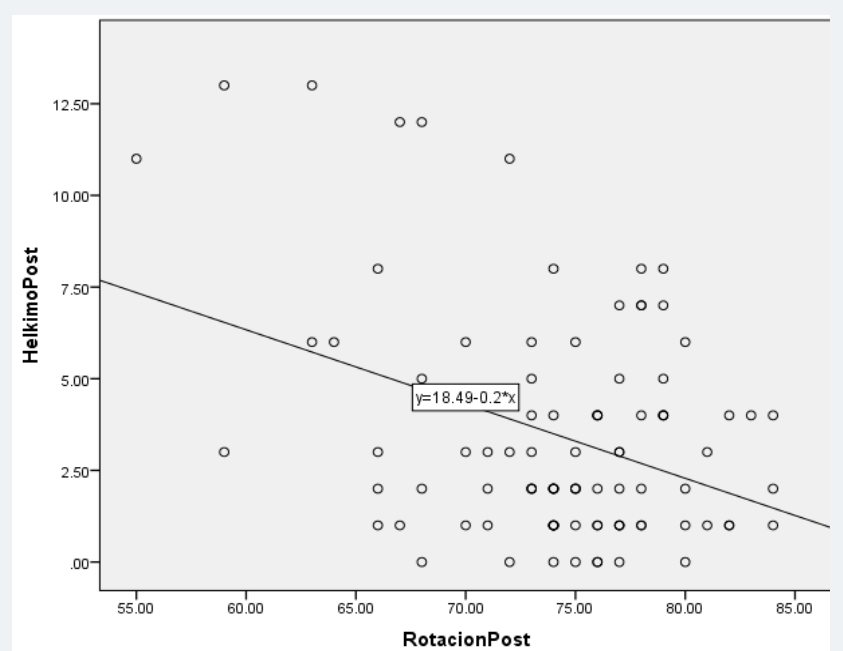

Figure 5: A stronger Pearson's correlation coefficient was found between mandibular condyle rotation (ConRot) and HADI $-0.367(p<0.01)$

a strong Pearson's correlation coefficient with a score of $-0.217(\mathrm{p}<0.036)$ as seen in figure 4 .

A stronger Pearson's correlation coefficient was found between mandibular condyle rotation (ConRot) and HADI $-0.367(\mathrm{p}<0.01)$ as seen in figure 5 .

No association could be found between HADI and anterior condyle displacement measured with P\&HmP or with lateral condylar rotation (ConRot).

\section{Discussion}

The main goal of most patients who undergo bilateral sagittal split osteotomies is to achieve a better aesthetic facial result. During examination and planning, it's fundamental to perform cephalometric measurements for an adequate prediction of final results and prevent causing evident clinical dysfunction. Orthognathic surgery displaces and modifies mandibular topography in planned predictable sites for which surgery is intended, but secondarily disturbs the anatomy of the mandibular condyle causing clinical dysfunction in the temporomandibular joint [5]. Surgery also changes the facial osseous and muscle / soft tissue balance) which will elicit signs and symptoms observed and described in HADI [11].

In the tomographic sagittal plane, antero-posterior displacement of the mandibular condyle is observed after BSSO, for which Pullinger \& Hollender designed a measuring method to establish a condylar relationship with the temporomandibular joint [15]. Later Pereira modified this method in which he did the same measurements using a resting position centered bite instead of a maximal intercuspation bite [12]. In the tomographic axial plane rotational condylar movements are observed after surgery despite of condylar transoperative repositioning, most condylar position studies have omitted this measurement and have measured the condyle bi-dimensionally only. Also in the axial tomographic plane lateromedial condylar movements and "sag" can be observed, but have been negligible during postoperative clinical examination $[8,16]$.

Other studies have focused on remodeling and displacement of the mandibular condyles, and established this changes as a physiological adaptation process of the TMJ, allowing major consequences related to occlusion to be avoided. Sometimes the adaptive capacity of the joint is exceeded, leading to the onset of a resorption process of the condyle, characterized by bone remodeling with a negative balance in the volume of the condyle [17]. These studies have shown no correlation between changes in condylar volume and joint spaces. Therefore, changes in joint spaces are more likely to 
be related to factors other than remodeling, such as condylar displacement. Superior, posterior and medial joint spaces are reduced after orthognathic surgery, changes not related to the amount of the mandibular advancement that could possibly relate to TMJ dysfunction. However the measurements were performed in 2-D examinations, making it impossible to evaluate medial-lateral and rotational alterations [18-20].

In this study we observed that posterior displacement and medial condylar rotation are the most representative and valuable, since they will evoke a negative clinical impact in BSSO patients [21]. Despite the latter, this study could not establish a movement prediction method for the mandibular condyle. Follow-up examinations after at least 6 months, allowing symptoms that could be related directly to the postsurgical recovery period, showed that even with a protocolized technique, a broad range of displacement and rotation of the condyles was observed.

Also, the aim of this study was to establish a relationship between condylar displacement/rotation and the clinical dysfunction index after BSSO, thus other variables such as fixation method, type of fixation, osteosynthesis material position and distribution, osteotomy types, association to bimaxillary surgery, and others were not considered, and could be subject to future studies as they could also modify the position of the mandibular condyles after surgery.

\section{Conclusion}

Condylar displacements are a consequence of BSSO and mandibular advancement. These displacements represent a relationship with a negative clinical impact, mostly medial rotation and posterior condylar displacement.

This study could not establish a quantitative relationship between condylar displacements and the presentation of signs and symptoms in the orthognathic surgery patient. Mandibular advancement, setback or rotation planned in cephalometry are predictable and reproducible, but condylar displacements secondary to these are not, being influenced also by masticatory muscles and soft tissue, that after changing position are subject to elongation and compression forces evoking signs and symptoms, sometimes worsening the dysfunction of the patients.

\section{References}

1. Fish LC, Epker BN, Sullivan CR. Orthognathic surgery: the correction of dentofacial deformities. J Oral Maxillofac Surg. 1993; 51(Suppl 1): 28-41. Ref.: https://tinyurl.com/y2m6l7js

2. American Association of Oral and Maxillofacial Surgeons. Parameters of care: clinical practice guidelines for oral and maxillofacial surgery (AAOMS Par Care 2012). J Oral Maxillofac Surg. 2012; 70: 107-136. Ref.: https://tinyurl.com/y28tl8ra

3. Sinko K, Jagsch B, Benes G, Millesi F, Fischmeister R. Facial aesthetics and the assignment of personality traits before and after orthognathic surgery. Int J Oral Maxillofac Surg. 2012; 41: 469476. Ref.: https://tinyurl.com/yyxjtdfs

4. Zins JE, Bruno J, Moreira-Gonzalez A, Bena J. Orthognathic surgery: is there a future? Plast Reconstr Surg. 2005; 116: 1442-1450. Ref.: https://tinyurl.com/y6qgmw9q

5. Posnick JC. Orthognathic Surgery, Principles and Practice. Elsevier Health Sciences. 2013; 61-68. Ref.: https://tinyurl.com/y2abqzmg

6. Bell WH, Schendel SA. Biologic basis for modification of the sagittal ramus split operation. $\mathrm{J}$ Oral Surg. 1977; 35: 362-369. Ref.: https://tinyurl.com/yys2sccm

7. Onizawa K, Schmelzen R, Vogt S. Alteration of temporomandibular joint symptoms after orthognathic surgery comparison with healthy volunteers. J Oral Maxillofac Surg. 1995; 53: 117-121. Ref.: https://tinyurl.com/y35vnktq

8. Panula K, Somppi M, Finne K, Oikarinen K. Effects of orthognathic surgery on temporomandibular joint dysfunction: a controlled prospective 4-year follow-up study. Int J Oral Maxillofac Surg. 2000; 29: 183-187. Ref.: https://tinyurl.com/yyktfy6y 
9. Kundert M, Hadjianghelou O. Condylar displacement after sagittal splitting of the mandibular rami. J Maxillofac Surg. 1980; 8: 278-287. Ref.: https://tinyurl.com/yyfr426z

10. Bagheri SC, Bell RB, Khan HA. Current Therapy in Oral and Maxillofacial Surgery. Elsevier Saunders; 2012. Mandibular Deficiency: Bilateral Sagittal Split Osteotomy. 617-626. Ref.: https://tinyurl.com/y4av8wkx

11. Helkimo M. Studies on function and dysfunction of the masticatory system. II. Index for anamnestic and clinical dysfunction and occlusal state. Swed Dent J. 1974: 67: 101-121. Ref.: https://tinyurl.com/y3tdjrc2

12. Pereira LJ, Gavião MB. Tomographic evaluation of TMJ in adolescents with temporomandibular disorders. Braz. Oral Res. 2004; 18: 208-214. Ref.: https://tinyurl.com/y6g43qzx

13. Pérez Garcidueñas CM, Malagón Hidalgo HO. Medición Tomográfica del ángulo cóndilo-mandibular en pacientes del servicio de cirugía plástica del Centro Médico ISSEMyM "Arturo Montiel Rojas" de 1 de enero de 2013 al 31 de diciembre de 2013. Trabajo de Tesis, Reg 009/14, Universidad Autónoma del Estado de México. 2014.

14. An SB, Park SB, Kim YI, Son WS. Effect of post-orthognathic surgery condylar axis changes on condylar morphology as deter- mined by 3-dimensional surface reconstruction. Angle Orthod. 2014; 84: 316-321. Ref.: https://tinyurl.com/y4ubab52

15. Pullinger AG, Hollender L, Solberg WK, Petersson A. A tomographic study of mandibular condyle position in an asymptomatic population. J Prosthet Dent. 1985; 53: 706-713. Ref.: https://tinyurl.com/yxfk22ek

16. Kadesjö N, Benchimol D, Falahat B, Näsström K, Shi XQ. Evaluation of the effective dose of cone beam $\mathrm{CT}$ and multislice $\mathrm{CT}$ for temporomandibular joint examinations at optimized exposure levels. Dentomaxillofac Radiol. 2015; 44: 20150041. Ref.: https://tinyurl.com/yxnrgpgu

17. Ferri J, Nicor R, Màes JM, Raoul G, Lauwers L. Condylar resorptions and orthodontic surgical treatment: state of the art. Int Orthod. 2016; 14: 503-527. Ref.: https://tinyurl.com/y5447neg

18. Kawamata A, Fujishita M, Nagahara K, Kanematu N, Niwa K, et al. Three-dimensional computed tomography evaluation of postsurgical condylar displacement after mandibular osteotomy. Oral Surg Oral Med Oral Pathol Oral Radiol Endod. 1998; 85: 371-376. Ref.: https://tinyurl.com/y2dmcchr

19. Alder ME, Deahl ST, Matteson SR, Van Sickels JE, Tiner BD, et al. Short-term changes of condylar position after sagittal split osteotomy for mandibular advancement. Oral Surg Oral Med Oral Pathol Oral Radiol Endod. 1999; 87: 159-165. Ref.: https://tinyurl.com/y2y6bbjn

20. Méndez-Manjón I, Guijarro-Martínez R, Valls-Ontañón A, Hernández-Alfaro F. Early changes in condylar position after mandibular advancement: a three-dimensional analysis. Int $\mathrm{J}$ Oral Maxillofac Surg. 2016; 45: 787-792. Ref.: https://tinyurl.com/y5uscdgy

21. Frey DR, Hatch JP, Van Sickels JE, Dolce C, Rugh JD. Effects of surgical mandibular advancement and rotation on signs and symptoms of temporomandibular disorder: a 2-year follow-up study. Am J Orthod Dentofacial Orthop. 2008; 133: 490.e1-8. Ref.: https://tinyurl.com/yxu6ep8m 